\title{
Inequalities of Čebyšev Type for Lipschitzian Functions in Banach Algebras
}

\author{
Marius V. Boldea
}

\begin{abstract}
In this paper we give some Čebyšev type norm inequalities for two Lipschitzian functions on Banach algebras. Some examples for power function, exponential and the resolvent functions are also provided.
\end{abstract}

AMS Subject Classification (2000). 47A63; 47A99.

Keywords. Banach algebras, Power series, Exponential function, Resolvent function, Norm inequalities

\section{Introduction}

Let $\mathcal{B}$ be an algebra. An algebra norm on $\mathcal{B}$ is a map $\|\cdot\|: \mathcal{B} \rightarrow[0, \infty)$ such that $(\mathcal{B},\|\cdot\|)$ is a normed space, and, further

$$
\|a b\| \leq\|a\|\|b\|
$$

for any $a, b \in \mathcal{B}$. The normed algebra $(\mathcal{B},\|\cdot\|)$ is a Banach algebra if $\|\cdot\|$ is a complete norm. We assume that the Banach algebra is unital, this means that $\mathcal{B}$ has an identity 1 and that $\|1\|=1$.

Let $\mathcal{B}$ be a unital algebra. An element $a \in \mathcal{B}$ is invertible if there exists an element $b \in \mathcal{B}$ with $a b=b a=1$. The element $b$ is unique; it is called the inverse of $a$ and written $a^{-1}$ or $\frac{1}{a}$.

The set of invertible elements of $\mathcal{B}$ is denoted by $\operatorname{Inv} \mathcal{B}$. If $a, b \in \operatorname{Inv} \mathcal{B}$ then $a b \in \operatorname{Inv} \mathcal{B}$ and $(a b)^{-1}=b^{-1} a^{-1}$. 
For a unital Banach algebra we also have:

(i) If $a \in \mathcal{B}$ and $\lim _{n \rightarrow \infty}\left\|a^{n}\right\|^{1 / n}<1$, then $1-a \in \operatorname{Inv} \mathcal{B}$;

(ii) $\{a \in \mathcal{B}:\|1-a\|<1\} \subset \operatorname{Inv} \mathcal{B}$;

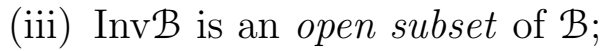

(iv) The map $\operatorname{Inv} \mathcal{B} \ni a \longmapsto a^{-1} \in \operatorname{Inv} \mathcal{B}$ is continuous.

For simplicity, we denote $\lambda 1$, where $\lambda \in \mathbb{C}$ and 1 is the identity of $\mathcal{B}$, by $\lambda$. The resolvent set of $a \in \mathcal{B}$ is defined by

$$
\rho(a):=\{\lambda \in \mathbb{C}: \lambda-a \in \operatorname{Inv} \mathcal{B}\} ;
$$

the spectrum of $a$ is $\sigma(a)$, the complement of $\rho(a)$ in $\mathbb{C}$, and the resolvent function of $a$ is $R_{a}: \rho(a) \rightarrow \operatorname{Inv} \mathcal{B}, R_{a}(\lambda):=(\lambda-a)^{-1}$. For each $\lambda, \gamma \in \rho(a)$ we have the identity

$$
R_{a}(\gamma)-R_{a}(\lambda)=(\lambda-\gamma) R_{a}(\lambda) R_{a}(\gamma)
$$

We also have that $\sigma(a) \subset\{\lambda \in \mathbb{C}:|\lambda| \leq\|a\|\}$. The spectral radius of $a$ is defined as $\nu(a)=\sup \{|\lambda|: \lambda \in \sigma(a)\}$. If $a, b$ are commuting elements in $\mathcal{B}$, i.e. $a b=b a$, then

$$
\nu(a b) \leq \nu(a) \nu(b) \text { and } \nu(a+b) \leq \nu(a)+\nu(b) .
$$

Let $f$ be an analytic functions on the open disk $D(0, R)$ given by the power series $f(\lambda):=\sum_{j=0}^{\infty} \alpha_{j} \lambda^{j}(|\lambda|<R)$. If $\nu(a)<R$, then the series $\sum_{j=0}^{\infty} \alpha_{j} a^{j}$ converges in the Banach algebra $\mathcal{B}$ because $\sum_{j=0}^{\infty}\left|\alpha_{j}\right|\left\|a^{j}\right\|<\infty$, and we can define $f(a)$ to be its sum. Clearly $f(a)$ is well defined and there are many examples of important functions on a Banach algebra $\mathcal{B}$ that can be constructed in this way. For instance, the exponential map on $\mathcal{B}$ denoted exp and defined as

$$
\exp a:=\sum_{j=0}^{\infty} \frac{1}{j !} a^{j} \text { for each } a \in \mathcal{B} .
$$

If $\mathcal{B}$ is not commutative, then many of the familiar properties of the exponential function from the scalar case do not hold. The following key formula is valid, however with the additional hypothesis of commutativity for $a$ and $b$ from $\mathcal{B}$

$$
\exp (a+b)=\exp (a) \exp (b) \text {. }
$$

In a general Banach algebra $\mathcal{B}$ it is difficult to determine the elements in the range of the exponential map $\exp (\mathcal{B})$, i.e. the elements which have a 
"logarithm". However, it is easy to see that if $a$ is an element in $B$ such that $\|1-a\|<1$, then $a$ is in $\exp (\mathcal{B})$. That follows from the fact that if we set

$$
b=-\sum_{n=1}^{\infty} \frac{1}{n}(1-a)^{n},
$$

then the series converges absolutely and, as in the scalar case, substituting this series into the series expansion for $\exp (b)$ yields $\exp (b)=a$.

It is known that if $x$ and $y$ are commuting, i.e. $x y=y x$, then the exponential function satisfies the property

$$
\exp (x) \exp (y)=\exp (y) \exp (x)=\exp (x+y) .
$$

Also, if $x$ is invertible and $a, b \in \mathbb{R}$ with $a<b$ then

$$
\int_{a}^{b} \exp (t x) d t=x^{-1}[\exp (b x)-\exp (a x)] .
$$

Moreover, if $x$ and $y$ are commuting and $y-x$ is invertible, then

$$
\begin{aligned}
\int_{0}^{1} \exp ((1-s) x+s y) d s & =\int_{0}^{1} \exp (s(y-x)) \exp (x) d s \\
& =\left(\int_{0}^{1} \exp (s(y-x)) d s\right) \exp (x) \\
& =(y-x)^{-1}[\exp (y-x)-I] \exp (x) \\
& =(y-x)^{-1}[\exp (y)-\exp (x)] .
\end{aligned}
$$

Inequalities for functions of operators in Hilbert spaces may be found in the papers [?SSD], [?SSDG] and in the recent monographs [?SSDBook1], [?SSDBook2] and the references therein. Let $\alpha_{n}$ be nonzero complex numbers and let

$$
R:=\frac{1}{\limsup \left|\alpha_{n}\right|^{\frac{1}{n}}} .
$$

Clearly $0 \leq R \leq \infty$, but we consider only the case $0<R \leq \infty$.

Denote by:

$$
D(0, R)= \begin{cases}\{\lambda \in \mathbb{C}:|\lambda|<R\}, & \text { if } R<\infty \\ \mathbb{C}, & \text { if } R=\infty,\end{cases}
$$

consider the functions:

$$
\lambda \mapsto f(\lambda): D(0, R) \rightarrow \mathbb{C}, f(\lambda):=\sum_{n=0}^{\infty} \alpha_{n} \lambda^{n}
$$


and

$$
\lambda \mapsto f_{A}(\lambda): D(0, R) \rightarrow \mathbb{C}, f_{A}(\lambda):=\sum_{n=0}^{\infty}\left|\alpha_{n}\right| \lambda^{n} .
$$

Let $\mathcal{B}$ be a unital Banach algebra and 1 its unity. Denote by

$$
B(0, R)= \begin{cases}\{x \in \mathcal{B}:\|x\|<R\}, & \text { if } R<\infty \\ \mathcal{B}, & \text { if } R=\infty .\end{cases}
$$

We associate to $f$ the map

$$
x \mapsto \widetilde{f}(x): B(0, R) \rightarrow \mathcal{B}, \widetilde{f}(x):=\sum_{n=0}^{\infty} \alpha_{n} x^{n} .
$$

Obviously, $\tilde{f}$ is correctly defined because the series $\sum_{n=0}^{\infty} \alpha_{n} x^{n}$ is absolutely convergent, since $\sum_{n=0}^{\infty}\left\|\alpha_{n} x^{n}\right\| \leq \sum_{n=0}^{\infty}\left|\alpha_{n}\right|\|x\|^{n}$.

The following result has been obtained in [?DBM].

Theorem 1.1. Let $f(\lambda)=\sum_{n=0}^{\infty} \alpha_{n} \lambda^{n}$ be a power series that is convergent on the open disk $D(0, R)$, with $R>0$. If $x, y \in \mathcal{B}$ with $x y=y x$ and $\|x\|,\|y\| \leq 1$, then we have for $\lambda \in \mathbb{C}$ with $|\lambda|<R$ the inequality:

$$
\begin{aligned}
& \|\tilde{f}(\lambda \cdot 1) \tilde{f}(\lambda x y)-\tilde{f}(\lambda x) \tilde{f}(\lambda y)\| \\
& \leq\|x-1\|\|y-1\|\left\{f_{A}(|\lambda|)\left[|\lambda| f_{A}^{\prime}(|\lambda|)+|\lambda|^{2} f_{A}^{\prime \prime}(|\lambda|)\right]-\left[|\lambda| f_{A}^{\prime}(|\lambda|)\right]^{2}\right\} .
\end{aligned}
$$

For other similar results see [?DBB] and [?DBM]. Motivated by the above results, in this paper we consider the similar problem to provide upper bounds for the Cebyšev quantity

$$
\left\|P_{n} \sum_{i=1}^{n} p_{i} F\left(x_{i}\right) G\left(y_{i}\right)-\sum_{i=1}^{n} p_{i} F\left(x_{i}\right) \sum_{i=1}^{n} p_{i} G\left(y_{i}\right)\right\|,
$$

where $F, G$ are some functions defined on a Banach algebra $\mathcal{B}, p_{i} \geq 0$ with $P_{n}:=\sum_{i=1}^{n} p_{i}>0$ and $x_{i}, y_{i} \in \mathcal{C}, i=1,2, \ldots, n$ where $\mathcal{C}$ is an appropriate subset of $\mathcal{B}$. For various results on Čebyšev's inequality in different settings, see [?A1]-[?SSD], [?cfo6b]-[?SSDBook2] and [?6b]-[?ZC].

\section{Some New Inequalities}

We say that the function $F: \mathcal{C} \subset \mathcal{B} \rightarrow \mathcal{B}$ is a Lipschitian with constant $L>0$ on the subset $\mathcal{C}$ of the Banach algebra $(\mathcal{B},\|\|$.$) if$

$$
\|F(x)-F(y)\| \leq L\|x-y\|
$$


for any $x, y \in \mathcal{C}$.

Theorem 2.1. Let $F, G: \mathcal{C} \subset \mathcal{B} \rightarrow \mathcal{B}$ be Lipschitian functions with constants $L>0$ and $K>0$. If $x_{i}, y_{i} \in \mathcal{C}, i=1,2, \ldots, n$ and $p_{i} \geq 0, i=1,2, \ldots, n$ with $P_{n}:=\sum_{i=1}^{n} p_{i}>0$, then we have:

$$
\begin{gathered}
\left\|P_{n} \sum_{i=1}^{n} p_{i} F\left(x_{i}\right) G\left(y_{i}\right)-\sum_{i=1}^{n} p_{i} F\left(x_{i}\right) \sum_{i=1}^{n} p_{i} G\left(y_{i}\right)\right\| \\
\quad \leq L K \sum_{1 \leq i<j \leq n} p_{i} p_{j} \sum_{l=i}^{j-1}\left\|\Delta x_{l}\right\| \sum_{s=i}^{j-1}\left\|\Delta y_{s}\right\|
\end{gathered}
$$

where $\Delta x_{l}$ is the forward difference, namely: $\Delta x_{l}=x_{l+1}-x_{l}, l=1, \ldots, n-1$. Proof. Since $F$ and $G$ are Lipschitian with the constants $L$ and $K$ we have:

$$
\left\|F\left(x_{i}\right)-F\left(x_{j}\right)\right\| \leq L\left\|x_{i}-x_{j}\right\|
$$

and

$$
\left\|G\left(y_{i}\right)-G\left(y_{j}\right)\right\| \leq K\left\|y_{i}-y_{j}\right\|
$$

for any $i, j \in\{1, \ldots, n\}$. If we multiply these inequalities we get

$$
\left\|F\left(x_{i}\right)-F\left(x_{j}\right)\right\|\left\|G\left(y_{i}\right)-G\left(y_{j}\right)\right\| \leq L K\left\|x_{i}-x_{j}\right\|\left\|y_{i}-y_{j}\right\| .
$$

Using the property of Banach algebra $\mathcal{B},\|u v\| \leq\|u\|\|v\|$, that for any $u, v \in$ $\mathcal{B}$ we have,

$$
\left\|\left(F\left(x_{i}\right)-F\left(x_{j}\right)\right)\left(G\left(y_{i}\right)-G\left(y_{j}\right)\right)\right\| \leq L K\left\|x_{i}-x_{j}\right\|\left\|y_{i}-y_{j}\right\|
$$

for any $i, j \in\{1, \ldots, n\}$, that is equivalent to:

$$
\begin{gathered}
\left\|F\left(x_{i}\right) G\left(y_{i}\right)-F\left(x_{j}\right) G\left(y_{i}\right)-F\left(x_{i}\right) G\left(y_{j}\right)+F\left(x_{j}\right) G\left(y_{j}\right)\right\| \\
\leq L K\left\|x_{i}-x_{j}\right\|\left\|y_{i}-y_{j}\right\|
\end{gathered}
$$

for any $i, j \in\{1, \ldots, n\}$. If we multiply (??) by $p_{i} p_{j}>0$ sum over $i$ and $j$ from 1 to $\mathrm{n}$ and use the generalised triangle inequality, we get:

$$
\left\|\sum_{i, j=1}^{n} p_{i} p_{j}\left(F\left(x_{i}\right) G\left(y_{i}\right)-F\left(x_{j}\right) G\left(y_{i}\right)-F\left(x_{i}\right) G\left(y_{j}\right)+F\left(x_{j}\right) G\left(y_{j}\right)\right)\right\|
$$




$$
\begin{gathered}
\leq \sum_{i, j=1}^{n} p_{i} p_{j}\left\|F\left(x_{i}\right) G\left(y_{i}\right)-F\left(x_{j}\right) G\left(y_{i}\right)-F\left(x_{i}\right) G\left(y_{j}\right)+F\left(x_{j}\right) G\left(y_{j}\right)\right\| \\
\leq L K \sum_{i, j=1}^{n} p_{i} p_{j}\left\|x_{i}-x_{j}\right\|\left\|y_{i}-y_{j}\right\| .
\end{gathered}
$$

Now, observe that

$$
\begin{gathered}
\sum_{i, j=1}^{n} p_{i} p_{j}\left(F\left(x_{i}\right) G\left(y_{i}\right)-F\left(x_{j}\right) G\left(y_{i}\right)-F\left(x_{i}\right) G\left(y_{j}\right)+F\left(x_{j}\right) G\left(y_{j}\right)\right) \\
=P_{n} \sum_{i=1}^{n} p_{i} F\left(x_{i}\right) G\left(y_{i}\right)-\sum_{j=1}^{n} p_{j} F\left(x_{j}\right) \sum_{i=1}^{n} p_{i} G\left(y_{i}\right) \\
-\sum_{i=1}^{n} p_{i} F\left(x_{i}\right) \sum_{j=1}^{n} p_{j} G\left(y_{j}\right)+P_{n} \sum_{j=1}^{n} p_{j} F\left(x_{j}\right) G\left(y_{j}\right) \\
=2\left(P_{n} \sum_{i=1}^{n} p_{i} F\left(x_{i}\right) G\left(y_{i}\right)-\sum_{i=1}^{n} p_{i} F\left(x_{i}\right) \sum_{i=1}^{n} p_{i} G\left(y_{i}\right)\right) .
\end{gathered}
$$

We also have, by the symmetry in the sum:

$$
\sum_{i, j=1}^{n} p_{i} p_{j}\left\|x_{i}-x_{j}\right\|\left\|y_{i}-y_{j}\right\|=2 \sum_{1 \leq i<j \leq n} p_{i} p_{j}\left\|x_{j}-x_{i}\right\|\left\|y_{j}-y_{i}\right\| .
$$

Moreover, we have $x_{j}-x_{i}=\sum_{l=1}^{j-1} \Delta x_{l}$ and $y_{j}-y_{i}=\sum_{s=1}^{j-1} \Delta y_{s}$ where $\Delta x_{l}:=x_{l+1}-x_{l}, l=i, \ldots, j-1$ and by the generalized triangle inequality we have:

$$
\left\|x_{j}-x_{i}\right\| \leq \sum_{l=i}^{j-1}\left\|\Delta x_{l}\right\|
$$

and

$$
\left\|y_{j}-y_{i}\right\| \leq \sum_{s=i}^{j-1}\left\|\Delta y_{s}\right\|
$$


By the inequality (??) and by (??) we then have:

$$
\sum_{i, j=1}^{n} p_{i} p_{j}\left\|x_{i}-x_{j}\right\|\left\|y_{i}-y_{j}\right\| \leq 2 \sum_{1 \leq i<j \leq n} p_{i} p_{j} \sum_{l=i}^{j-1}\left\|\Delta x_{l}\right\| \sum_{s=i}^{j-1}\left\|\Delta y_{s}\right\| .
$$

Now, by making use of (??), (??) and (??) we get the desired result (??).

Corollary 2.2. With the assumptions of Theorem 1 we have:

$$
\begin{aligned}
& \left\|P_{n} \sum_{i=1}^{n} p_{i} F\left(x_{i}\right) G\left(y_{i}\right)-\sum_{i=1}^{n} p_{i} F\left(x_{i}\right) \sum_{i=1}^{n} p_{i} G\left(y_{i}\right)\right\| \\
& \leq \frac{1}{2} L K\left(P_{n}^{2}-\sum_{i=1}^{n} p_{i}^{2}\right) \sum_{k=1}^{j-1}\left\|\Delta x_{k}\right\| \sum_{k=1}^{n-1}\left\|\Delta y_{k}\right\| .
\end{aligned}
$$

Proof. It is obvious that for all $1 \leq i<j \leq n$ we have that:

$$
\sum_{l=i}^{j-1}\left\|\Delta x_{l}\right\| \leq \sum_{k=1}^{n-1}\left\|\Delta x_{k}\right\|
$$

and

$$
\sum_{s=i}^{j-1}\left\|\Delta y_{s}\right\| \leq \sum_{k=1}^{n-1}\left\|\Delta y_{k}\right\|
$$

Then

$$
\sum_{1 \leq i<j \leq n} p_{i} p_{j} \sum_{l=i}^{j-1}\left\|\Delta x_{l}\right\| \sum_{s=i}^{j-1}\left\|\Delta y_{s}\right\| \leq \sum_{1 \leq i<j \leq n} p_{i} p_{j} \sum_{k=1}^{n-1}\left\|\Delta x_{k}\right\| \sum_{k=1}^{n-1}\left\|\Delta y_{k}\right\| .
$$

Now, let observe that:

$$
\begin{aligned}
\sum_{1 \leq i<j \leq n} p_{i} p_{j} & =\frac{1}{2}\left[\sum_{i, j=1}^{n} p_{i} p_{j}-\sum_{i=j} p_{i} p_{j}\right] \\
& =\frac{1}{2}\left[\sum_{i=1}^{n} p_{i} \sum_{j=1}^{n} p_{j}-\sum_{i=1}^{n} p_{i}^{2}\right] \\
& =\frac{1}{2}\left(P_{n}^{2}-\sum_{i=1}^{n} p_{i}^{2}\right) .
\end{aligned}
$$

Using (??) we deduce (??). 
Corollary 2.3. With the assumptions of Theorem 1 we have:

$$
\begin{array}{r}
\left\|P_{n} \sum_{i=1}^{n} p_{i} F\left(x_{i}\right) G\left(y_{i}\right)-\sum_{i=1}^{n} p_{i} F\left(x_{i}\right) \sum_{i=1}^{n} p_{i} G\left(y_{i}\right)\right\| \\
\leq L K \sum_{1 \leq i<j \leq n}(j-i) p_{i} p_{j}\left(\sum_{k=1}^{n-1}\left\|\Delta x_{k}\right\|^{p}\right)^{\frac{1}{p}}\left(\sum_{k=1}^{n-1}\left\|\Delta y_{k}\right\|^{q}\right)^{\frac{1}{q}}
\end{array}
$$

when $p, q>1$ and $\frac{1}{p}+\frac{1}{q}=1$.

Proof. Using Hölder's discrete inequality, we can state that

$$
\sum_{l=i}^{j-1}\left\|\Delta x_{l}\right\| \leq(j-i)^{\frac{1}{q}}\left(\sum_{l=i}^{j-1}\left\|\Delta x_{l}\right\|^{p}\right)^{\frac{1}{p}}
$$

and

$$
\sum_{s=i}^{j-1}\left\|\Delta y_{s}\right\| \leq(j-i)^{\frac{1}{p}}\left(\sum_{s=i}^{j-1}\left\|\Delta y_{s}\right\|^{q}\right)^{\frac{1}{q}}
$$

where $j-1 \geq i, p, q>1$ and $\frac{1}{p}+\frac{1}{q}=1$, and then, by multiplication we have

$$
\begin{gathered}
\sum_{1 \leq i<j \leq n} p_{i} p_{j} \sum_{l=i}^{j-1}\left\|\Delta x_{l}\right\| \sum_{s=i}^{j-1}\left\|\Delta y_{s}\right\| \\
\leq \sum_{1 \leq i<j \leq n} p_{i} p_{j}(j-i)^{\frac{1}{p}+\frac{1}{q}}\left(\sum_{l=i}^{j-1}\left\|\Delta x_{l}\right\|^{p}\right)^{\frac{1}{p}}\left(\sum_{s=i}^{j-1}\left\|\Delta y_{s}\right\|^{q}\right)^{\frac{1}{q}} \\
=\sum_{1 \leq i<j \leq n} p_{i} p_{j}(j-i)\left(\sum_{l=i}^{j-1}\left\|\Delta x_{l}\right\|^{p}\right)^{\frac{1}{p}}\left(\sum_{s=i}^{j-1}\left\|\Delta y_{s}\right\|^{q}\right)^{\frac{1}{q}} \\
\leq \sum_{1 \leq i<j \leq n} p_{i} p_{j}(j-i)\left(\sum_{k=1}^{n-1}\left\|\Delta x_{k}\right\|^{p}\right)^{\frac{1}{p}}\left(\sum_{k=1}^{n-1}\left\|\Delta y_{k}\right\|^{q}\right)^{\frac{1}{q}}
\end{gathered}
$$

and the corollary is proved. 
Corollary 2.4. With the assumptions of Theorem 1 we have:

$$
\begin{gathered}
\left\|P_{n} \sum_{i=1}^{n} p_{i} F\left(x_{i}\right) G\left(y_{i}\right)-\sum_{i=1}^{n} p_{i} F\left(x_{i}\right) \sum_{i=1}^{n} p_{i} G\left(y_{i}\right)\right\| \\
\leq L K\left[P_{n} \sum_{i=1}^{n} i^{2} p_{i}-\left(\sum_{i=1}^{n} i p_{i}\right)^{2}\right] \max _{1 \leq k \leq n-1}\left\|\Delta x_{k}\right\| \max _{1 \leq k \leq n-1}\left\|\Delta y_{k}\right\| .
\end{gathered}
$$

Proof. We have

$$
\sum_{l=i}^{j-1}\left\|\Delta x_{l}\right\| \leq(j-i) \underset{l=1, n-1}{\max }\left\|\Delta x_{l}\right\|
$$

and

$$
\sum_{s=i}^{j-1}\left\|\Delta y_{s}\right\| \leq(j-i) \max _{s=1, n-1}\left\|\Delta y_{s}\right\|
$$

Then

$$
\begin{gathered}
\sum_{1 \leq i<j \leq n} p_{i} p_{j} \sum_{l=i}^{j-1}\left\|\Delta x_{l}\right\| \sum_{s=i}^{j-1}\left\|\Delta y_{s}\right\| \\
\leq \sum_{1 \leq i<j \leq n} p_{i} p_{j}(j-i)^{2} \max _{l=\overline{1, n-1}}\left\|\Delta x_{l}\right\| \max _{s=\overline{1, n-1}}\left\|\Delta y_{s}\right\| \\
=\left[\sum_{i=1}^{n} p_{i} \sum_{i=1}^{n} i^{2} p_{i}-\left(\sum_{i=1}^{n} i p_{i}\right)^{2}\right] \max _{l=\overline{1, n-1}}\left\|\Delta x_{l}\right\| \max _{s=\overline{1, n-1}}\left\|\Delta y_{s}\right\|
\end{gathered}
$$

and the corollary is proved.

\section{Some Applications}

In [?SSD11] S. S. Dragomir proved the following result:

Lemma 3.1. Let $f(z)=\sum_{n=0}^{\infty} \alpha_{n} z^{n}$ be a function defined by power series with complex coefficients and convergent on the open disk $D(0, r) \subset \mathbb{C}, R>0$ and let $f_{a}(\lambda):=\sum_{n=0}^{\infty}\left|\alpha_{n}\right| \lambda^{n}$. For any $x, y \in \mathcal{B}$ with $\|x\|,\|y\| \leq M<R$ we have:

$$
\|f(y)-f(x)\| \leq f_{a}^{\prime}(M)\|y-x\| .
$$


If we take $f(z)=z^{p}, p \in \mathbb{N}, p \geq 1$ and assume that $x, y \in \mathcal{B}$ with $\|x\|,\|y\| \leq M$ then we have

$$
\left\|y^{p}-x^{p}\right\| \leq p M^{p-1}\|y-x\|
$$

If we take $f(z)=\exp (\mu z)$, with $\mu \in \mathbb{R}, \mu \neq 0$ and assume that $x, y \in \mathcal{B}$ with $\|x\|,\|y\| \leq M$ then we have

$$
\|\exp (\mu y)-\exp (\mu x)\| \leq|\mu| \exp (\mu M)\|y-x\| .
$$

If we write the inequality (??) for $F(z)=z^{p}, G(z)=z^{q}$, with $p, q \in \mathbb{N}$, $p, q \geq 1$ then we have for $\left\|x_{i}\right\|,\left\|y_{i}\right\| \leq M, i \in\{1,2, \ldots, n\}$ that

$$
\begin{gathered}
\left\|P_{n} \sum_{i=1}^{n} p_{i} x_{i}^{p} y_{i}^{q}-\sum_{i=1}^{n} p_{i} x_{i}^{p} \sum_{i=1}^{n} p_{i} y_{i}^{q}\right\| \\
\leq p q M^{p+q-2} \sum_{1 \leq i<j \leq n} p_{i} p_{j} \sum_{l=i}^{j-1}\left\|\Delta x_{l}\right\| \sum_{s=i}^{j-1}\left\|\Delta y_{s}\right\| .
\end{gathered}
$$

If $p=q$ and $x_{i}$ commutes with $y_{i}$ for each $i \in\{1,2, \ldots, n\}$, then we get from (??) that:

$$
\begin{gathered}
\left\|P_{n} \sum_{i=1}^{n} p_{i}\left(x_{i} y_{i}\right)^{p}-\sum_{i=1}^{n} p_{i} x_{i}^{p} \sum_{i=1}^{n} p_{i} y_{i}^{p}\right\| \\
\leq p^{2} M^{2 p-2} \sum_{1 \leq i<j \leq n} p_{i} p_{j} \sum_{l=i}^{j-1}\left\|\Delta x_{l}\right\| \sum_{s=i}^{j-1}\left\|\Delta y_{s}\right\| .
\end{gathered}
$$

In particular, for $x_{i}=y_{i}$ and $p=q, i \in\{1,2, \ldots, n\}$, we get

$$
\begin{gathered}
\left\|P_{n} \sum_{i=1}^{n} p_{i}\left(x_{i}\right)^{2 p}-\left(\sum_{i=1}^{n} p_{i} x_{i}^{p}\right)^{2}\right\| \\
\leq p^{2} M^{2 p-2} \sum_{1 \leq i<j \leq n} p_{i} p_{j}\left(\sum_{l=i}^{j-1}\left\|\Delta x_{l}\right\|\right)^{2} .
\end{gathered}
$$


Now, if we write the inequality (??) for the functions $F(z)=\exp (\mu z)$ and $G(z)=\exp (\nu z)$, with $\mu, \nu \in \mathbb{R}, \mu, \nu \neq 0$ we get for $\left\|x_{i}\right\|,\left\|y_{i}\right\| \leq M$, for $i \in\{1,2, \ldots, n\}$ that

$$
\begin{aligned}
& \left\|P_{n} \sum_{i=1}^{n} p_{i} \exp \left(\mu x_{i}\right) \exp \left(\nu y_{i}\right)-\sum_{i=1}^{n} p_{i} \exp \left(\mu x_{i}\right) \sum_{i=1}^{n} p_{i} \exp \left(\nu y_{i}\right)\right\| \\
& \quad \leq|\mu \nu| \exp [(\mu+\nu) M] \sum_{1 \leq i<j \leq n} p_{i} p_{j} \sum_{l=i}^{j-1}\left\|\Delta x_{l}\right\| \sum_{s=i}^{j-1}\left\|\Delta y_{s}\right\|
\end{aligned}
$$

If $x_{i}$ commutes with $y_{i}$ for each $i \in\{1,2, \ldots, n\}$, then from (??) we get:

$$
\begin{aligned}
& \left\|P_{n} \sum_{i=1}^{n} p_{i} \exp \left(\mu x_{i}+\nu y_{i}\right)-\sum_{i=1}^{n} p_{i} \exp \left(\mu x_{i}\right) \sum_{i=1}^{n} p_{i} \exp \left(\nu y_{i}\right)\right\| \\
& \leq|\mu \nu| \exp [(\mu+\nu) M] \sum_{1 \leq i<j \leq n} p_{i} p_{j} \sum_{l=i}^{j-1}\left\|\Delta x_{l}\right\| \sum_{s=i}^{j-1}\left\|\Delta y_{s}\right\| .
\end{aligned}
$$

In particular, for $x_{i}=y_{i}$ and $\mu=\nu, i \in\{1,2, \ldots, n\}$, we get:

$$
\begin{aligned}
& \left\|P_{n} \sum_{i=1}^{n} p_{i} \exp \left(2 \mu x_{i}\right)-\left(\sum_{i=1}^{n} p_{i} \exp \left(\mu x_{i}\right)\right)^{2}\right\| \\
& \leq|\mu|^{2} \exp (2 \mu M) \sum_{1 \leq i<j \leq n} p_{i} p_{j}\left(\sum_{l=i}^{j-1}\left\|\Delta x_{l}\right\|\right)^{2} .
\end{aligned}
$$

Consider now the function $F_{p}(z)=\left(1-z^{p}\right)^{-1}=\sum_{n=0}^{\infty} z^{n p}$ for $p \geq 1$ a natural number. Then $F_{p}^{\prime}(z)=-\left(1-z^{p}\right)^{-2}\left(-p z^{p-1}\right)=p\left(1-z^{p}\right)^{-2} z^{p-1}$. If $M<1$, then $F_{p}^{\prime}(M)=p\left(1-M^{p}\right)^{-2} M^{p-1}$.

We have then $F_{p}(x)=\left(1-x^{p}\right)^{-1}, x \in \mathcal{B},\|x\|<1, p \geq 1$ is Lipschitzian with the constant $p\left(1-M^{p}\right)^{-2} M^{p-1}$ and the function $G_{q}(x)=\left(1-x^{q}\right)^{-1}$, $x \in \mathcal{B},\|x\|<1, q \geq 1$ is Lipschitzian with the constant $q\left(1-M^{q}\right)^{-2} M^{q-1}$. Therefore, by using Theorem 2.1 for $x_{i}, y_{i} \in \mathcal{B}$ with $\left\|x_{i}\right\|,\left\|y_{i}\right\| \leq M<1$, $i \in\{1,2, \ldots, n\}$, we get for $p_{i} \geq 0, i \in\{1,2, \ldots, n\}$ that

$$
\left\|P_{n} \sum_{i=1}^{n} p_{i}\left(1-x_{i}^{p}\right)^{-1}\left(1-y_{i}^{q}\right)^{-1}-\sum_{i=1}^{n} p_{i}\left(1-x_{i}^{p}\right)^{-1} \sum_{i=1}^{n} p_{i}\left(1-y_{i}^{q}\right)^{-1}\right\|
$$




$$
\leq p q\left(1-M^{p}\right)^{-2}\left(1-M^{q}\right)^{-2} M^{p+q-2} \sum_{1 \leq i<j \leq n} p_{i} p_{j} \sum_{l=i}^{j-1}\left\|\Delta x_{l}\right\| \sum_{s=i}^{j-1}\left\|\Delta y_{s}\right\| .
$$

In particular for $p=q$ and $x_{i}=y_{i}$ for each $i \in\{1,2, \ldots, n\}$, we get from (??) that:

$$
\begin{gathered}
\left\|P_{n} \sum_{i=1}^{n} p_{i}\left(1-x_{i}^{p}\right)^{-2}-\left(\sum_{i=1}^{n} p_{i}\left(1-x_{i}^{p}\right)^{-1}\right)^{2}\right\|^{2} \\
\leq p^{2}\left(1-M^{p}\right)^{-4} M^{2 p-2} \sum_{1 \leq i<j \leq n} p_{i} p_{j}\left(\sum_{l=i}^{j-1}\left\|\Delta x_{l}\right\|\right)^{2} .
\end{gathered}
$$

Finally, we notice that if one uses the upper bounds from Corollaries 2.2 2.4 that one can get further upper bounds in the examples outlined above. The details are omitted.

\section{References}

[1] G. A. Anastassiou, Grüss type inequalities for the Stieltjes integral, Nonlinear Funct. Anal. Appl., 12 (4), (2007), 583-593

[2] G. A. Anastassiou, Chebyshev-Grüss type and comparison of integral means inequalities for the Stieltjes integral, Panamer. Math. J., 17 (3), (2007), 91-109

[3] G. A. Anastassiou, Chebyshev-Grüss type inequalities via Euler type and Fink identities, Math. Comput. Modelling, 45 (9-10), (2007), 1189-1200

[4] M. Biernacki, Sur une inégalité entre les intégrales due à Tchebyscheff, Ann. Univ. Mariae Curie-Sklodowska, A5, (1951), 23-29

[5] K. Boukerrioua and A. Guezane-Lakoud, On generalization of Čebyšev type inequalities, J. Inequal. Pure Appl. Math., 8 (2, Article 55), (2007), 4 pp.

[6] P. L. Čebyšev, O približennyh vyraženijah odnih integralov čerez drugie, Soobšćenija $i$ protokoly zasedanǐ Matemmatičeskogo občestva pri Imperatorskom Har'kovskom Universitete, 2(93-98)

[7] P.L. Čebyšev, Ob odnom rjade, dostavljajušćem predel'nye veličiny integralov pri razloženii podintegral'noŭ funkcii na množeteli, Priloženi $k 57$ tomu Zapisok Imp. Akad. Nauk, 4

[8] P. Cerone, On a Čebyšev-type functional and Grüss-like bounds, Math. Inequal. Appl., 9 (1), (2006), 87-102 
[9] P. Cerone, On Chebyshev functional bounds, Differential $\&$ difference equations and applications, (2006), 267-277

[10] P. Cerone, On some results involving the Čebyšev functional and its generalisations, J. Inequal. Pure Appl. Math., 4 (3, Article 55), (2003), 17 pp.

[11] P. Cerone and S. S. Dragomir, A refinement of the Grüss inequality and applications, Tamkang J. Math., 38 (1), (2007), 37-49

$[12]$ P. Cerone and S. S. Dragomir, Chebychev functional bounds using Ostrowski seminorms, Southeast Asian Bull. Math., 28 (2), (2004), 219-228

[13] P. Cerone and S. S. Dragomir, New bounds for the Čebyšev functional, Appl. Math. Lett., 18 (6), (2005), 603-611

[14] S. S. Dragomir, Inequalities for the Čebyšev functional of two functions of selfadjoint operators in Hilbert spaces, Aust. J. Math. Anal. $\& 3$ Appl., 6 (1, Article 7), (2009), $1-58$

[15] S. S. Dragomir, Some inequalities for power series of selfadjoint operators in Hilbert spaces via reverses of the Schwarz inequality, Integral Transforms Spec. Funct., 20 (9-10), (2009), 757-767

[16] S. S. Dragomir, Inequalities for power series in Banach Algebras, SUT J. of Math., 50 (1), (2014), 25-45

[17] S. S. Dragomir, On some improvements of Čebyšev's inequality for sequences and integrals, Studia Univ. Babeş-Bolyai, Mathematica (Romania), XXXV (4), (1990), $35-40$

[18] S. S. Dragomir, Some improvement of Čebyšev's inequality for isotonic functionals, Atti. Sem. Mat. Fis. Univ. Modena (Italy), 41, (1993), 473-481

[19] S.S. Dragomir, A generalization of Grüss' inequality in inner product spaces and applications, 237, (1999), 74-82

[20] S. S. Dragomir, Some discrete inequalities of Grüss type and applications in guessing theory, Honam Math. J., 21 (1), (1999), 145-156

[21] S. S. Dragomir, Grüss inequality in inner product spaces, The Australian Math Soc. Gazette, 26 (2), (1999), 66-70

[22] S. S. Dragomir, A Grüss type integral inequality for mappings of $r$-Hölder's type and applications for trapezoid formula, Tamkang J. of Math., 31 (1), (2000), 43-47

[23] S.S. Dragomir, Some integral inequalities of Grüss type, Indian J. of Pure and Appl. Math., 31 (4), (2000), 397-415

[24] S. S. Dragomir, On the Ostrowski inequality for the Riemann-Stieltjes integral $\int_{a}^{b} f(t) d u(t)$, where $f$ is of Hölder type and $u$ is of bounded variation and applications, J. KSIAM, 5 (1), (2001), 35-45

[25] S. S. Dragomir, Some Grüss type inequalities in inner product spaces, J. Inequal. Pure \&3 Appl. Math., 4 (2), (2003), Article 42, (Online: http://jipam.vu.edu.au/article.php?sid=280) 
[26] S. S. Dragomir, Reverses of Schwarz, triangle and Bessel inequalities in inner product spaces, J. Inequal. Pure $\&$ Appl. Math., 5 (3), (2004), Article 76. (Online: http://jipam.vu.edu.au/article.php?sid=432)

[27] S.S. Dragomir, New reverses of Schwarz, triangle and Bessel inequalities in inner product spaces, Austral. J. Math. Anal. \& Applics., 1 (1), (2004), Article 1. (Online: http://ajmaa.org/cgi-bin/paper.pl?string=nrstbiips.tex )

[28] S. S. Dragomir, On the Čebyšev's inequality for weighted means, Acta Math. Hungar., 104 (4), (2004), 345-355

[29] S.S. Dragomir, On Bessel and Grüss inequalities for orthornormal families in inner product spaces, Bull. Austral. Math. Soc., 69 (2), (2004), 327-340

[30] S. S. Dragomir, Advances in Inequalities of the Schwarz, Grüss and Bessel Type in Inner Product Spaces, Nova Science Publishers Inc, New York, 2005

[31] S. S. Dragomir, Reverses of the Schwarz inequality in inner product spaces generalising a Klamkin-McLenaghan result, Bull. Austral. Math. Soc., 73 (1), (2006), 69-78

[32] S. S. Dragomir, Some new Grüss' type inequalities for functions of selfadjoint operators in Hilbert spaces, RGMIA Res. Rep. Coll., 11 (e), (2008), Art. 12

[33] S. S. Dragomir, Inequalities for the Čebyšev functional of two functions of selfadjoint operators in Hilbert spaces, RGMIA Res. Rep. Coll., 11 (e), (2008), Art. 17

[34] S. S. Dragomir, Some inequalities for the Cebyšev functional of two functions of selfadjoint operators in Hilbert spaces, RGMIA Res. Rep. Coll., 11 (e), (2008), Art. 8

[35] S. S. Dragomir, Springer Briefs in Mathematics. Springer, New York, 2012

[36] S. S. Dragomir, Operator Inequalities of Ostrowski and Trapezoidal Type, Springer Briefs in Mathematics. Springer, New York, 2012

[37] S. S. Dragomir, M. V. Boldea, C. Busse, and M. Megan, Norm inequalities of Čebyšev type for power series in Banach algebras, J. Inequal. Appl., 2014, 2014:294

[38] S. S. Dragomir, M. V. Boldea, and M. Megan, New bounds for Čebyšev functional for power series in Banach algebras via a Grüss'-Lupaş type inequality, Preprint RGMIA Res. Rep. Coll., 17, (2014)

[39] S. S. Dragomir and G.L. Booth, On a Grüss-Lupaş type inequality and its applications for the estimation of p-moments of guessing mappings, Mathematical Communications, 5, (2000), 117-126

[40] S. S. Dragomir and I. Fedotov, An inequality of Grüss' type for Riemann-Stieltjes integral and applications for special means, Tamkang J. of Math., 29 (4), (1998), 286292

[41] S. S. Dragomir and B. Mond, Some mappings associated with Čebyšev's inequality for sequences of real numbers, Bull. Allahabad Math. Soc., 8/9, (1993/94), $37-55$

[42] S.S. Dragomir and J.E. Pečarić, Refinements of some inequalities for isotonic linear functionals, L'Anal. Num. Théor de L'Approx.(Romania), 18 (1), (1989), 6165 
[43] S. S. Dragomir, J. Pečarić, and J. Sándor, The Chebyshev inequality in preHilbertian spaces. II., Proceedings of the Third Symposium of Mathematics and its Applications (Timişoara, 1989), (1990), 75-78

[44] S. S. Dragomir and J. Sándor, The Chebyshev inequality in pre-Hilbertian spaces. I., Proceedings of the Second Symposium of Mathematics and its Applications (Timişoara, 1987), (1988), 61-64

[45] A. M. Fink, A treatise on Grüss' inequality, Analytic and Geometric Inequalities, Math. Appl., 478, (1999), 93-113

[46] G. Grüss, Über das Maximum des absoluten Betrages von $\frac{1}{b-a} \int_{a}^{b} f(x) g(x) d x-$ $\frac{1}{(b-a)^{2}} \int_{a}^{b} f(x) d x \int_{a}^{b} g(x) d x$, Math. Z., 39, (1935), 215-226

[47] Z. Liu, Refinement of an inequality of Grüss type for Riemann-Stieltjes integral, Soochow J. Math., 30 (4), (2004), 483-489

[48] A. Matković, J. Pečarić, and I. Perić, A variant of Jensen's inequality of Mercer's type for operators with applications, Linear Algebra Appl., 418 (2-3), (2006), 551-564

[49] D. S. Mitrinović and J.E. Pečarić, History, variations and generalizations of the Čebyšev inequality and question of some priorities. II, Rad Jugoslav. Akad. Znan. Umjet. No., 450, (1990), 139-156

[50] D. S. Mitrinović and J.E. Pečarić, On an identity of D.Z. Djoković, Prilozi Mak. Akad.Nauk. Umj. (Skopje), 12 (1), (1991), 21-22

[51] D. S. Mitrinović and P.M. Vasić, History, variations and generalisations of the Čebyšev inequality and the question of some priorities, Univ. Beograd. Publ. Elektrotehn. Fak. Ser. Mat. Fiz., 461-497, (1974), 1-30

[52] B. G. Pachpatte, A note on Čebyšev type inequalities, An. Ştiinţ. Univ. Al. I. Cuza Iaşi. Mat. (N.S.)(Romania), 53 (1), (2007), 97-102

[53] B. G. Pachpatte, New Čebyšev type inequalities involving functions of two and three variables, Soochow J. Math., 33 (4), (2007), 569-577

[54] B. G. Pachpatte, A note on Grüss type inequalities via Cauchy's mean value theorem, Math. Inequal. Appl., 11 (1), (2008), 75-80

[55] J. Pečarić, Remarks on Biernacki's generalization of Čebyšev's inequality, Ann. Univ. Mariae Curie-Sklodowska Sect. A, 47, (1993), 116-122

[56] J. E. Pečarić and S.S. Dragomir, Some remarks on Čebyšev's inequality, L'Anal. Num. Théor de L'Approx., 19 (1), (1990), 58-65

[57] C.-J. Zhao and W.-S. Cheung, On multivariate Grüss inequalities, J. Inequal. Appl., 2008, Art. ID 249438, 8 pp.

Marius V. Boldea

Department Mathematics and Statistics,

Banat University of Agricultural Sciences and Veterinary Medicine Timişoara

119 Calea Aradului, Timişoara, România

E-mail: marius.boldea@usab-tm.ro 
Received: 7.08.2015

Accepted: 26.10.2016 